\title{
ENTRE AS RELAÇÕES DE FORÇA E O CONSENSO: AS POLÍTICAS ANTIMIGRATÓRIAS E OS TRABALHADORES-CASSACOS NO CONTEXTO DAS SECAS DA DÉCADA DE 1950
}

\author{
Between power relations and consensus: Anti-immigration policies \\ and monkey workers in the context of the 1950s droughts
}

Lara de Castro*

\begin{abstract}
Resumo: Durante as estiagens na década de 1950, diversas frentes de serviços foram organizadas no Nordeste pelo Poder Executivo, via Ministério da Viação e Obras Públicas, sob a justificativa de empregar os pobres das secas e controlar também as migrações para os estados de outras regiões. No Ceará, milhares de trabalhadores foram alistados em obras de açudagem, estradas de rodagem, redes de irrigação, eletricidade, prédios públicos, entre outras, protagonizando a edificação de uma volumosa estrutura em todo o estado. Um estudo das políticas antimigratórias, das quais faziam parte as frentes de trabalho que empregou os sujeitos desta pesquisa e as medidas de contenção de migrantes nas fronteiras e uma apreciação geral sobre o cenário em que se assentou o universo de trabalho das obras públicas durante as secas de 1950 são objeto desse artigo.
\end{abstract}

Palavras-chave: Políticas antimigratórias, secas e problemas sociais.

\begin{abstract}
During the droughts happened in the 50's of the 20th century many "work fronts" were organized in the Brazilian Northeast by Executive Powers through Ministério da Viação e Obras Públicas, whose goals were hire poor refugees and control the migrations to other Brazilian regions. Such actions were based on public constructions ruled by some official agencies. In the State of Ceará thousands of workers were enlisted in constructions of weirs, roads, irrigations canals, electricity lines, public buildings, among others, playing fundamental role into the edification of a huge physical infrastructure throughout the State. A study of anti-immigration policies, which included the work fronts employed by the subjects of this research and the measures to contain migrants at the borders and a general appreciation of the scenario on which the universe of public works work was based during droughts 1950s are the subject of this article.
\end{abstract}

Keywords: anti-immigration policies, droughts and social problems.

Em 1915, pela primeira vez, o governo federal articulou-se com autoridades públicas e particulares da região, atualmente conhecida como Nordeste, para organizar e coordenar um volumoso programa de frentes de emergência de "combate às secas", no intuito de mitigar os problemas sociais avaliados como efeito da estiagem daquele ano. Tais obras, criadas urgentemente após a declaração daquela seca e conduzidas pela "Comissão de Obras Novas Contra as Secas", visavam deliberadamente evitar o êxodo da mão de obra dispersa pelas estiagens, proporcionando ocupação aos trabalhadores, mas também havia a intenção de impedir os tumultos provocados pela chegada de aglomerações de retirantes aos núcleos urbanos (FERREIRA, 2009). ${ }^{1}$

\footnotetext{
* Professora do Programa de Pós-Graduação da Universidade Federal do Amapá (PPGH-UNIFAP) e dos cursos de graduação em história UNIFAP. E-mail: laravcf@gmail.com

${ }^{1}$ Essas observações são resultantes da pesquisa de mestrado, realizada na Universidade Federal da Bahia, entre 2007 e 2009. A comissão em questão, "Obras Novas Contra as Secas", ainda não havia sido objeto de estudo. Por isso, a historiografia menciona o ano de 1932 como marco para a instauração de "frentes
} 
O emprego de trabalhadores pobres em obras públicas de grande porte, ou em serviços organizados localmente durante as secas, não era novidade desde a metade do século XIX. Afinal, desde esse período, as autoridades passaram a entender que as construções públicas ordinariamente conduzidas independentemente das secas poderiam servir ao propósito de aplacar as "agitações feitas pelos retirantes" nas cidades, quando as estiagens ocorriam. Nesse sentido, pode-se dizer que as vagas em obras passam também gradativamente a ser consideradas entre as respostas dadas às multidões de retirantes que solicitavam emprego e alimento (NEVES, 2002). ${ }^{2}$

A novidade das políticas ativadas para combater a seca de 1915 foi a intervenção organizada e diretiva do governo federal que, através da criação de uma comissão, tomou para si a responsabilidade na execução de frentes emergenciais de trabalho. Chamada de Obras Novas Contra as Secas, essa comissão atuou paralela e autonomamente em relação à Inspetoria de Obras Contra as Secas (IOCS), até 1919, utilizando regulamentos e até mesmo alguns funcionários desta instituição, agindo em todos os estados do polígono das secas, dando início a várias obras com o objetivo declarado de ocupar retirantes e conter a migração. Tratava-se, entre outras coisas, de dar maior celeridade à liberação dos recursos vindos do Ministério de Viação e Obras Públicas (MVOP) para o combate às estiagens, garantindo exclusividade e independência na gestão dos recursos.

A partir desse momento, além de aproveitar as construções já existentes para empregar os retirantes, conforme era feito eventualmente, passou-se a estabelecer um plano sistematizado de obras que era acionado no momento das secas, cuja execução era centralizada pelo governo federal e que associava os socorros dados aos pobres em tempos de estiagem ao trabalho nas frentes emergenciais. Agora, caberia ao Estado não somente dotar os sertões semiáridos de uma infraestrutura hídrica capaz de suportar as estiagens, como dele seria também recorrentemente cobrado o dever de criar obras especialmente com a finalidade de ocupar e fixar em seus locais de origem milhares de obreiros. Assim sendo, esse momento concretizou uma mudança nas políticas de Estado em tempos de secas.

Essa iniciativa de atacar obras com claros objetivos de evitar o êxodo foi fortalecendo-se ao longo da primeira metade do século XX. Ao lado disso, a política de incentivo e subsídio da migração, ${ }^{3}$ tão cara aos representantes políticos e donos de propriedades no XIX, perdeu espaço nos planos governamentais durante as secas. No entanto, é bom lembrar que um proposital hiato nesses projetos de Estado, depois de 1915, foi a Batalha da Borracha na Amazônia do início dos anos 1940, quando diversos órgãos públicos instituíram uma forte propaganda para impulsionar a

de emergência" em épocas secas, ou seja, a organização de um conjunto de obras, centralizadas federalmente, com o objetivo de empregar retirantes.

2 Em sua pesquisa, Neves estudou acontecimentos de 1877 até a década de 1950, visando demonstrar a consolidação de uma tradição de protestos em tempos de secas. Na concepção do autor, as obras, a doação de alimentos, passagens, etc. estão entre as respostas do poder público aos movimentos e saques dos retirantes durante as estiagens.

3 Sobre o ofício dos "paroaras": Cf. CARDOSO, Antonio Alexandre Isidio. Nem sina, Nem acaso: a tessitura das migrações entre a Província do Ceará e o território amazônico. Fortaleza, Mestrado em História Social - Universidade Federal do Ceará, 2011.Outras políticas antimigratórias foram os “campos de concentração" das secas. Sobre isso: RIOS, Kênia Sousa. Campos de concentração no Ceará: isolamento e poder na Seca de 1932. $2^{a}$ edição. Fortaleza: Museu do Ceará, 2006. NEVES, Frederico. Curral de bárbaros: Os campos de concentração no Ceara (1915 e 1932). Revista Brasileira de História 15, n. 29, 1995.

4 Batalha da Borracha foi um programa de emergência, que ocorreu durante a Segunda Guerra Mundial, para tentar suprir o déficit da borracha nos Estados Unidos. Nesse contexto, muitos trabalhadores, especialmente nordestinos, foram arregimentados para labutar nos seringais da Amazônia. Estima-se que cerca de 50.000 indivíduos migraram para o Norte e, destes, quase metade desapareceu ou morreu. Cf: SECRETO, 2007; COSTA, 2008. 
ida de trabalhadores nordestinos rumo à extração de látex. Certamente, a instalação da comissão de "Obras Novas", assim como outras frentes de trabalho nas secas posteriores, não cessou absolutamente a migração. Numerosas pessoas, em diferentes momentos, cruzaram as fronteiras dos estados semiáridos, fosse via passagens subsidiadas, com recursos obtidos pela venda de seus pertences, ou através dos "paroaras" e redes de parentesco.

Embora se saiba que os trabalhadores não seguiam resignados os projetos do Estado, existiam planos cuidadosamente arquitetados para os trabalhadores do "não-litoral" que precisam ser mencionados. Com as políticas antimigratórias, pretendia-se mantê-los exatamente em seus locais de origem e, caso resolvessem financiar a migração, que fosse preferencialmente para outras áreas consideradas do Interior brasileiro, como aconteceu na Batalha da Borracha. Até porque a temida inversão do fluxo de correntes de povoamento poderia causar um esvaziamento da reserva de mão de obra do campo, algo que prejudicava a ambicionada integração, num plano geral, e o abastecimento de alimentos nas cidades, os interesses de grupos políticos, donos de propriedades fundiárias e de outros negócios, no plano local.

Cerca de dez anos depois da Batalha da Borracha, autoridades públicas e particulares organizaram um plano de obras, durante as secas de 1951-1953 e 1958, objetivando novamente controlar a mão de obra dispersa. ${ }^{5}$ É fundamental sempre lembrar, aliás, que as frentes estreadas em períodos de estiagem devem ser consideradas também como estratégias de sobrevivência elaboradas pelos próprios trabalhadores, já que os pobres não esperavam mais esgotar-se na miséria, antecipavamse e muito cedo procuravam os núcleos urbanos na tentativa de garantir comida e emprego. ${ }^{6}$

Assim, diversos trabalhadores foram arregimentados na década de 1950 para labutar na edificação, restauração e conservação de obras organizadas por órgãos como o Departamento Nacional de Obras Contra as Secas (DNOCS) e Departamento Nacional de Estradas de Rodagem (DNER). As frentes de trabalho foram organizadas em obras já em andamento, ditas permanentes, mas especialmente nas acionadas durante as estiagens, chamadas de emergência. Estas, conforme boletim do DNOCS, ' diferente daquelas, se "destinavam a eliminar o desemprego nos períodos de estiagem", tendo "em vista manter a população no seu próprio ecúmeno", evitando "concentrações humanas improvisadas" e os "inconvenientes do trabalho a grandes distâncias". Daí a necessária "elaboração antecipada" de projetos para serem executados logo que a seca fosse alarmada.

Fora a expressa finalidade de ocupar e fixar trabalhadores, admitindo também o incômodo que os agrupamentos de pessoas causavam, as frentes de emergência carregavam características diferentes das demais obras públicas regulares. Mesmo ativadas com créditos especiais, sustentadas com o discurso do amparo, seus rarefeitos orçamentos não davam conta de empregar os numerosos pobres das secas. O excesso de braços, por sua vez, também reduzia a receita que resultava em

\footnotetext{
${ }^{5} \mathrm{~A}$ pesquisa sobre as obras públicas em tempos de secas articulada a uma complexa teia de interesses que envolvia autoridades políticas locais e nacionais, donos de terras, comerciantes, engenheiros e outros agentes dos órgãos públicos envolvidos, e, primordialmente, o estudo da experiência dos trabalhadorescassacos e suas famílias no universo das frentes de serviços das secas, o cotidiano, alistamentos, moradia, lida, alimentação, saúde-doença, acidentes, enfim, a luta pela garantia da vida foi objeto de análise da tese de doutorado de minha autoria intitulada "cassacos: trabalhadores na lida contra a fome e a degradação em tempos de secas (Ceará, anos 1950)" (FERREIRA, 2016) .

${ }^{6}$ Citarei alguns trabalhos que, de alguma forma, versam sobre a utilização da mão de obra de retirantes em obras públicas em tempos de secas, situando as "obras contra as secas" entre as obras de socorros públicos. SILVA, 2003; CÂNDIDO, 2005. Os demais trabalhos que se concentram nos estudos sobre a presença dos trabalhadores retirantes nas ditas "obras contra as secas", entre elas, obras permanentes e de emergência: FERREIRA, 2009; LIMA, 2010; MONTEIRO, 2012. CANDIDO, 2014.

7 DNOCS. Boletim. Rio de Janeiro: DNOCS/MVOP, v. 19, n. 3, fevereiro de 1959, p.32.
} 
parcos provimentos aos operários. Eram obras geralmente pequenas, pensadas para durar o ano de estiagem, por isso, ofereciam terríveis condições de alojamento, insalubres e improvisados, faltando água até para beber.

Diversos documentos do DNOCS, fontes literárias, entrevistas e jornais atestam que as condições de existência dos trabalhadores eram piores nas frentes de emergências, mesmo se comparada às outras obras públicas regulares que recebiam obreiros em tempos de secas. Longe de se pretender fazer uma espécie de comparação da "desgraça" - o que seria problemático e objetivamente muito difícil - deve-se considerar que havia diferentes tipos de construções que serviam de "socorro público" durante as secas, cujas distinções implicavam também em peculiaridades no universo do trabalho que nelas se organizava. Ao reuni-las numa mesma esteira, deve-se cuidar para não sintetizar e homogeneizar também as experiências dos obreiros, nos períodos de secas.

De qualquer modo, na década de 1950, diversos retirantes foram ocupados nas obras públicas durante as secas, tendo como motivação evitar a dispersão de braços. Se a instalação dessas frentes de trabalho nas construções foi o principal recurso acionado pelo Estado como parte das políticas migratórias, o armamento de barreiras nas saídas rumo ao Sudeste também funcionou como estratégia para tentar impedir os deslocamentos. Ainda assim, muitos migraram para longe à revelia do desejo do Estado, outros, por diversos motivos, permaneceram nos seus locais de origem e tornaram-se trabalhadores-cassacos nas obras.

\section{Aspectos da conjuntura}

No intuito de diminuir certos desníveis socioeconômicos entre os centros mais dinâmicos e áreas tidas como subdesenvolvidas, como o Nordeste - também a Amazônia -, o Estado brasileiro promoveu a criação de uma série de agências de desenvolvimento e infraestrutura. Assim, novos órgãos regionais surgiram já no fim da década de 1940, como a Companhia Hidrelétrica do São Francisco (CHESF), Comissão do Vale do São Francisco (CVSF), em seguida, a Superintendência de Desenvolvimento do Vale do São Francisco (SUVALE) e a atual Companhia de Desenvolvimento dos Vales do São Francisco e do Parnaíba (CODEVASF). Da mesma forma, na década de 1950, visando facilitar linhas de crédito, empréstimos e outras questões financeiras, criou-se o Banco do Nordeste do Brasil (BNB), tendo como principal aporte de recursos o Fundo das Secas.

Depois do Decreto-Lei 8.486, de 28 de dezembro de 1945, que reorganizou a Inspetoria Federal de Obras Contra as Secas (IFOCS), que passou a denominar-se Departamento Nacional de Obras Contra as Secas (DNOCS), essa instituição retomou alguns trabalhos, saindo de uma morosidade que se prolongava há alguns anos. O principal órgão empregador durante as secas também fortaleceu seus projetos através do estreitamento de laços com outras instituições durante o segundo governo Vargas, com o BNB, por exemplo. O banco colaboraria, "através do escritório técnico de estudos econômicos", no "exame dos problemas da região a cargo do DNOCS". Este, por sua vez, prestaria "ao banco a assistência técnica", algo previsto na Lei 1.649. O DNOCS também operou juntamente à CHESF na eletrificação de cidades do sertão nordestino.

No plano internacional o DNOCS manteve suas relações com o United States Bureau of Reclamation (USBR). As duas instituições concordavam com a política de combate às estiagens com foco no acúmulo de água em reservatórios. Importa dizer que destacados profissionais do USBR deram assistência técnica aos projetos do DNOCS. Além disso, engenheiros desta e de outras instituições receberam treinamento da agência estadunidense. Ainda mais, diversas construções 
do USBR também igualmente serviram como frentes de trabalho nos EUA. ${ }^{8}$

No segundo governo Vargas a construção de barragens voltou a ter fôlego, mas se acreditava que o atraso do Nordeste seria superado também pela irrigação e outras benfeitorias que viriam através da água acumulada em açudes. Fora isso, as rodovias também tiveram amplo papel nessa gestão. Com Sousa Lima à frente do Ministério da Viação e Obras Públicas e Vinícius Berredo, integrante da comissão mista Brasil-EUA, dirigindo o DNOCS, muitas estradas foram construídas, especialmente durante as secas do primeiro triênio da década de 1950. Durante a administração de José Américo de Almeida, no Ministério da Viação e Obras Públicas (MVOP), projetos de rodovias já passavam de 100 no primeiro trimestre de 1953, obras que seriam realizadas pelo Departamento Nacional de Estradas de Rodagem (DNER) e pelo DNOCS. ${ }^{9}$

A partir de 1956, com o presidente Juscelino Kubistchek, as iniciativas desenvolvimentistas fortaleceram-se. No Sudeste, o Plano de Metas priorizou a indústria com foco na implantação do parque automobilístico, em São Paulo. Enquanto isso, no Nordeste, discutia-se a desigualdade regional como entrave ao desenvolvimento do país, elencando como principais medidas "a industrialização autônoma", a "transformação da economia agrícola das faixas úmidas" e "das zonas semiáridas". Estes debates foram promovidos especialmente pelo Grupo Nacional de Desenvolvimento do Nordeste (GTDN), sob a coordenação de Celso Furtado, e resultaram na criação da Superintendência do Desenvolvimento do Nordeste (SUDENE), em fins da década de 1950 (LIMA, 2009, p.113-114)

Nesse segundo momento, aliás, ocorreu uma reorientação na política em torno das secas. Se até meados da década de 1950 ainda persistia a ideia de "combater" as secas (mediante a modificação do meio natural), tendo o acúmulo de água como mola-mestra fundamental, no segundo momento, em vez de "combater" as estiagens, começava-se a se pensar em "conviver" (através da modernização técnica e econômica das atividades) com o semiárido. Acreditava-se que não bastava reter água era necessário investir na qualidade do solo e dar maior fôlego à construção de estradas.

Portanto, na segunda metade da dezena de 1950, após a eleição de JK, o discurso já era que soluções paliativas, como emprego de retirantes em frentes de trabalho, tornavam o sertanejo um indigente remunerado. A ideia agora era criar meios para assalariar os trabalhadores do campo, pensamento que era fruto de algumas propostas de reorientações nas políticas em torno das secas. O principal órgão envolvido historicamente nas ações de combate às secas era o DNOCS, embora ele tenha feito aparente oposição à criação de uma nova instituição (SUDENE - que tinha à frente Celso Furtado), expandiu alguns projetos que se aproximavam das discussões realizadas por Celso Furtado e o GTDN na gestação da SUDENE.

Por outro lado, se com Juscelino Kubistchek defendia-se que a resolução dos problemas

\footnotetext{
8 Na verdade, em 1902, sete anos antes do atual DNOCS ser designado para operar no semiárido brasileiro, USBR foi criado como agência de recursos hídricos, implantando centenas de barragens ao longo do século XX. Durante a grande depressão, com o programa Civilian Conservation Corps Legacy (CCCL) inaugurado por Roosevelt, foram autorizados projetos com a dupla finalidade de desenvolver a infraestrutura e fornecer ocupação em obras públicas aos desempregados. Outras construções também foram implantadas posteriormente, nos anos 1940 e 1950. Cf: PFAFF, 2010; PFAFF, 2001, 31-39; SALMOND, 1965, p. 75-88; SOURCE, 1992, p. 229-249.

9 DNOCS. Relatório de obras executadas em 1951 (apresentado pelo diretor Eng. ${ }^{\circ}$ Vinícius Berredo). Rio de Janeiro: MVOP/DNOCS, 1952; DNOCS. Relatório de obras executadas em 1954 (apresentado pelo diretor Eng. ${ }^{\circ}$ Luiz Mendes). Rio de Janeiro: MVOP/DNOCS, 1955; DNOCS. Relatório das atividades de 1951 (Apresentado ao Presidente da República pelo Eng. ${ }^{\circ}$ Álvaro de Souza Lima - ministro da Viação e Obras Públicas). Rio de Janeiro: MVOP/Serviço de Documentação, 1951; DNOCS. Relatório das atividades de 1952. Rio de Janeiro: MVOP/Serviço de Documentação, 1953.
} 
nordestinos perderia peso na ótica da engenharia hidráulica para ganhar força no plano econômico e do desenvolvimento, pode-se dizer que o plano de prevenção contra as estiagens não superou a solução hidráulica. Defendida e celebrada nos anteriores cinquenta anos de combate às secas, a prática da construção de grandes obras de acúmulo de água permaneceu consideravelmente enérgica, no governo JK, com a edificação dos maiores reservatórios até então levantados no Brasil: Orós e Banabuiú. Mantinha-se, então, a ideia de que a seca causava a pobreza e que tal obstáculo seria sobrepujado através do acúmulo d'água. A "solução hidráulica" - materializada nas grandes obras - seria o instrumento salvacionista, situação que permanece forte nas políticas em torno das secas até hoje - a exemplo da famigerada transposição do rio São Francisco.

Algumas práticas clientelistas históricas também foram mantidas. Se o DNOCS manteve a ação de construção de açudes e obras complementares especialmente dentro de propriedades particulares, beneficiando-as (MEDEIROS, 1983, p.76), a SUDENE reforçou o exercício do favorecimento em proveito dos fazendeiros. Empréstimos bancários, financiamentos de projetos, continuariam a dotar muitas terras de uma infraestrutura que a valorizava economicamente, servindo, do mesmo modo, como atração e fixação de trabalhadores (CARVALHO, 1991, p. 20). O DNOCS, mas também a SUDENE, reforçaram, através dos deveres assumidos pelo Estado, a assistência aos retirantes em tempos de secas. Não havendo mais a proteção dos coronéis aos seus trabalhadores em períodos de estiagem, com a quebra do "pacto paternalista", sob a política desenvolvida pelo DNOCS e pela SUDENE, as práticas baseadas nos termos da reciprocidade ainda permaneceram fortes. O Estado auxilia os sertanejos e ao mesmo tempo também não deixa de garantir outras formas de proteção aos donos de terra. Isto, pode-se pensar, contribui para pôr em questão todo o discurso, reforçado por estudiosos, de mudança abrupta nas políticas em torno da seca a partir da inauguração de um novo cenário em fins da década de 1950, que teve como principal medida a organização do GTDN e a criação da SUDENE.

Em suma, a ideia de combater as secas que solidificou as políticas em torno delas, até metade do século XX, defendia a mudança das condições naturais do sertão árido. Mesmo que as soluções para o problema das estiagens tivessem como eixo o florestamento, a abertura de estradas, o uso de técnicas e métodos apropriados a baixa umidade (dry-farming), a principal delas era a solução hidráulica, com foco na açudagem. No fim da década de 1950, as ações em torno das secas começaram a ser orientadas pela busca da convivência com o semiárido através da modernização econômica e técnica das atividades produtivas, sem necessariamente ter a pretensão de superar o problema naturalmente.

Assim, a política em torno das estiagens, que tinha a SUDENE e o DNOCS como principais órgãos executores, apesar de sofrer mudanças a partir da segunda metade da dezena de 1950, não enfraqueceu, do modo como foi projetado, práticas que eram associadas aos projetos anteriores em torno das secas. Não obstante sejam visíveis os primeiros passos rumo ao pensamento de conviver com a seca e não mais combatê-la, as antigas ações da solução hidráulica, do clientelismo e das frentes de trabalho (como meio de ocupar trabalhadores rurais nas secas) continuaram a existir, demostrando, portanto, que as políticas em torno das secas não obedecem a um "antes e depois da SUDENE". 10

10 Até o governo do presidente Fernando Henrique Cardoso, as frentes de emergência das secas existiram. Somente na primeira administração do governo do presidente Luiz Inácio Lula da Silva tais frentes foram extintas. Com Lula, durante as estiagens, as pessoas não precisaram mais trabalhar num regime análogo à escravidão em obras públicas para garantir a comida. Ao meu entender isso se tornou viável pela ampla política de combate à fome, com destaque especial ao programa do "bolsa família". 
Na região Nordeste do Brasil, é de se entender que essas políticas continuavam a ter como umas das motivações principais o problema histórico da dispersão migratória de trabalhadores, ganhando celeridade em anos de secas. Em 1956, a preocupação com "homem do campo" e seu deslocamento teve o reforço da pressão da igreja católica num encontro de bispos, em Campina Grande, que discutiu não somente o amparo aos "retirantes", "pobres de cristo", mas também a possível influência que comunistas e outros ativistas políticos pudessem exercer sobre a população de migrantes. Era enfatizada pelos bispos uma mudança na estrutura agrária, para que propostas de comunistas não pudessem empolgar trabalhadores rurais, a exemplo do que estava ocorrendo com as ligas camponesas.

Para isso, volumosos créditos foram liberados para construir obras que se constituíssem em investimento no âmbito da política desenvolvimentista. Espalhar construções pelo Interior do país, portanto, atendia à sede por integração e ocupação dos espaços supostamente "vazios", obsessão que percorre a década de 1940 e 1950, representada também pela construção de Brasília no governo de Juscelino Kubitschek. Ao mesmo tempo, desejava-se com as obras ocupar os desempregados das secas, mantendo-os calmos e longe dos centros, e represar a migração de braços para outros estados, funcionando com política antimigratória.

\section{Frentes de trabalho: ocupar e fixar}

A ideia de evitar o êxodo faz parte de um anterior projeto de integração nacional, no qual o caminho natural das correntes migratórias deveria ser sempre no sentido litoral-sertão, o contrário, como explana Verônica Secreto, "era visto como um erro bistórico" (SECRETO, 2007, p.7). O povoamento do Interior é uma preocupação anterior ao Brasil republicano e remete aos tempos da América Portuguesa. Dessa forma, a "marcha para o Oeste", organizada no primeiro governo Vargas, trouxe novamente à baila a preocupação com a extensão territorial do Brasil. Aliás, proposta que foi direcionada de forma contundente à ampla região amazônica e ao Nordeste.

O Nordeste, a Amazônia e o Centro-Oeste, com efeito, faziam parte do Brasil sertanejo miserável, iletrado e atrasado, frente ao Brasil litorâneo soberbo, europeizado e erudito. Sob a argumentação de aproximar as distantes áreas fronteiriças, necessitadas de defesa e amparo aos moldes citadinos, ao restante do Brasil, foram implantados diversos projetos. Preocupados com a ocupação e desenvolvimento foram instaladas colônias agrícolas no Nordeste e na Amazônia, além disso, ocorreu uma verdadeira cruzada com expedições de estudos e realização de diversas obras no Interior do país, demonstrando, aliás, a presença do reflexo de uma antiga equação positivista do XIX: conhecer, prever e agir.

Dessa maneira, com o retorno de Getúlio Vargas e seus ideais de integração e com a frenética incursão pelos sertões que marcou a gestão de Juscelino Kubistchek, acreditava-se que era o momento de romper de vez com a mística da Amazônia dos "cenários maravilhosos" e "clima tórrido" (PAZ, 2014, p.34-35), com as distâncias e "vazios" do Centro-Oeste e com o Nordeste árido e hostil. Esses lugares reforçavam, no discurso oficial, a antiga dualidade sertão-litoral, que tinha amparo em estudos políticos, científicos e literários. Conforme Secreto, tudo que não era litoral era sertão e as inserções no Interior do Brasil deveriam equilibrar os desníveis existentes (SECRETO, 2007, p.19).

A necessidade de povoamento e fixação dos trabalhadores concorria para a ambicionada ocupação dos territórios do sertão do Brasil, tarefa tida como uma das mais importantes no projeto de integração nacional. No Ceará, a percepção das estiagens como fenômeno natural que tornava 
o lugar ainda mais atrasado pelo ambiente inóspito era algo que seria controverso apenas de modo parcial pelo uso do saber técnico-científico. Entretanto, embora considerado um meio, sazonalmente, inapropriado para viver e labutar, o governo não considerava o sertão nordestino tão vazio quanto outras áreas do Brasil. O medo era do despovoamento que as secas poderiam ocasionar. Por isso, as iniciativas eram organizadas mais no sentido de fixar os trabalhadores em obras públicas pelo interior enquanto as calamidades da estiagem durassem.

Então, a integração de áreas ditas isoladas por meio do emprego dos trabalhadores em campos de obras tinha um valor incomensurável para o projeto de ocupação, fixação e desenvolvimento do Interior do país. As obras contra as secas eram erigidas justamente em áreas relativamente isoladas do interior. Se as centenas de obras executadas em áreas distantes dos centros urbanos desejavam anunciar o progresso de uma região, as características destas influenciaram várias marcas imprimidas ao universo de trabalho dos pobres nas secas.

Em 1951, conforme o Correio do Ceará," para evitar que "flagelados" batessem "à porta da capital" cearense e de outras cidades, construções foram concentradas em pontos estratégicos do interior, distribuindo comida e colocação em obras. ${ }^{12}$ Segundo um telegrama enviado ao governador do Ceará e publicado pelo mesmo periódico, as bancadas nordestinas na Câmara e no Senado Federal concordavam sobre o posicionamento de evitar o êxodo por meio da abertura de frentes de emergência. A deliberação acertada sobre aquela seca confluiu para que uma ação coordenada fosse efetivada no Nordeste com o objetivo de "obter medidas imediatas e urgentes para evitar o êxodo das populações flageladas" e fornecer trabalho. ${ }^{13}$

Jornais do Sudeste, como se observa melhor adiante, demonstravam a preocupação com a migração volumosa de "retirantes" para os seus estados e divulgavam recorrentemente as ações previstas pelas autoridades para solucionar esse problema. Ao mesmo tempo em que o jornal Estado de São Paulo celebrava as providências anunciadas pelo ministro do MVOP, Sousa Lima, de construção de estradas e açudes para concentrar "retirantes", "estancando o êxodo", ${ }^{14}$ o Correio da Manhã do Rio de Janeiro informava que Getúlio Vargas já havia aprovado medidas de impedimento da saída de nordestinos dos seus lugares de origem. ${ }^{15}$

Dessa forma, inúmeras obras foram iniciadas e prosseguidas como estratégia do Estado para, entre outros, manter trabalhadores dentro de suas fronteiras de origem. As estradas estiveram entre as principais construções que serviram como frentes de trabalho durante a década de 1950. Centenas de rodovias, como explanou o diretor Vinícius Berredo, em relatório, foram estreadas quando "a crise climática obrigou a dar início a novos serviços para permitir o acesso de flagelados que afluíam à procura de trabalhos". ${ }^{16}$ Além disso, pequenos, médios e grandes açudes, como o Araras, o Orós e o Banabuiú, no Ceará, finalmente iniciaram suas construções com o alarde das secas, tornando-se também centros de "socorros públicos".

Entretanto, por mais que diversas obras tenham sido iniciadas em diversos cantos do Ceará

\footnotetext{
11 Biblioteca Pública do Ceará. Correio do Ceará. 09/03/1951. Com exceção do jornal Estado de São Paulo, que foi consultado no Arquivo Edgard Leuenroth (AEL) - Unicamp, do periódico Diário de Notícias, que foi consultado na Biblioteca Pública da Bahia, e dos jornais consultados no Arquivo Público do estado do Rio de Janeiro (Aperj), os demais utilizados nessa tese encontram-se Biblioteca Pública do estado do Ceará.

12 Também tratam desse assunto o Tribuna do Ceará, 17/4/1951; 28/4/1951.

13 Correio do Ceará, 3/4/1951.

14 Estado de São Paulo, 4/6/1951.

${ }^{15}$ Arquivo Público do Estado do Rio de Janeiro (APERJ), fundo DPS, Flagelados, D 497. Correio da Manhã, 1/6/1951. Fls.3.

16 DNOCS. Relatório de obras executadas em 1951(apresentado pelo Diretor Vinícius Berredo). Rio de Janeiro: DNOCS/MVOP, 1951, p.4.
} 
objetivando ocupar pobres e evitar a migração para outros estados, elas não foram suficientes para abarcar a cifra de necessitados atingidos pelos problemas sociais da seca de 1951. A escassez de vagas frente ao número de necessitados gerou bastante celeuma, chegando aos ouvidos do governo no Rio de Janeiro. Então, na tentativa de impedir que aquele excedente de braços cruzasse as fronteiras, José Américo, Ministro da Viação e Obras Públicas de 1951-1954, tornou urgente "uma campanha" para inviabilizar a saída de "famílias inteiras" dos seus estados de origem (CAMARGO, Aspácia, 1984, p. 5).

Mesmo com mudanças nos quadros políticos, a obsessão por integrar as regiões e garantir a imobilidade dos seus trabalhadores atravessou os anos cinquenta. Em 1958, aquela que ficou conhecida como a "grande seca" motivou uma reunião que agregou setores públicos do DNOCS, DNER, Exército, Comissão Federal de Abastecimentos e Preços (COFAP), Instituto Nacional de Imigração e Colonização (INIC), Ministério do Trabalho, da Viação e Obras públicas e representantes da Conferência Nacional de Bispos, da Legião Brasileira de Assistência e da Fundação das Pioneiras Sociais, esta tendo à frente Sarah Kubistchek. A resolução imediata amplamente apoiada por essa elite política, social e religiosa foi "assistir" os pobres através do emprego em diversas obras que igualmente serviriam para "fixar" o trabalhador do campo. A decisão, portanto, foi liberar créditos especiais para intensificação, ampliação e antecipação de obras ocupando todos que procurassem "os escritórios do DNOCS e do DNER", especialmente “onde maior fosse" a "aglomeração", "em obras tão próximas quanto possível” dos seus locais de moradia, "a fim de evitar o êxodo". ${ }^{17}$

Dessa forma, o DNOCS iniciou prontamente cerca de 145 frentes de trabalho ${ }^{18} \mathrm{em}$ todo o Interior do Nordeste e o DNER recebeu "instruções para reter o retirante" mediante a construção de rodovias, estas com especial encargo de "impedir o êxodo desordenado e tulmutuado para o Sul" . ${ }^{19}$ Além disso, o DNER, em alguns momentos, também agiu em cooperação com a polícia para fiscalizar e barrar a saída de migrantes pelas fronteiras do Nordeste. ${ }^{20}$

O Ceará, aliás, foi o estado mais beneficiado com verbas nesta seca, assim como em outras estiagens, motivo para bancadas de outros estados, como a da Bahia, reclamar maiores orçamentos, principalmente diante do tamanho do seu território no polígono das secas. Então, se as frentes de trabalho foram a principal medida acionada para contornar os problemas ocasionados durante as secas, elas acabavam por justificar pedidos de maiores alcances de verbas, até por serem o recurso fundamental das políticas antimigratórias. Dessa forma, pode-se dizer que a disparada emergencial rumo a instalações de obras não era monocausal. Além da clássica motivação apontada, que é a execução de obras para responder às pressões dos retirantes em busca por trabalho e comida, as obras eram organizadas também para evitar a migração, como se percebe, atendendo aos fazendeiros ansiosos por não perder braços para o êxodo e valorizar economicamente suas terras e a políticos desejosos de verbas em seus municípios para assegurar melhoramentos e manter fixos seus votos.

As obras emergenciais, portanto, foram o recurso principal da intensa política antimigratória dos anos 1950. Ao lado disso, o Estado, através do MVOP, INIC, DNER e DNOCS, organizou-se para conter a saída de pessoas das fronteiras do Nordeste, acionando até a polícia para

17 DNOCS. Boletim. Rio de Janeiro: DNOCS/MVOP, n.2, vol.18, novembro de 1959, p.34.

18 DNOCS. Boletim. Rio de Janeiro: DNOCS/MVOP, vol. 18 n2, nov. de 1958, pp.34,35.

19 DNOCS. Boletim. Rio de Janeiro: Departamento Nacional de Obras Contra as Secas/Ministério da Viação e Obras Públicas, agosto de 1959, p. 36.

20 Correio do Ceará. 3/4/1951. 
aparelhar as estradas e tentar barrar o fluxo do êxodo. Assim, onde o projeto das frentes de serviços fracassasse, atuaria a força coercitiva para conter a migração. Ainda que existissem empresários de diferentes setores interessados na mão de obra barata dos nordestinos, os que decidiram ir em direção ao Sudeste, enfrentaram um verdadeiro arsenal de estratégias da política oficial. Mesmo assim, milhares de pessoas cruzaram os limites dos seus lugares de nascença.

Sendo assim, as frentes de emergência das obras contra as secas faziam parte da política oficial antimigratória acionada nas secas da década de 1950 para fixar trabalhadores nos seus locais de origem. Em menor medida, outro recurso de tentativa de controle da migração foi a instalação de postos de vigilância nas fronteiras rumo ao Sudeste conduzidos por órgãos federais, estaduais e polícia. Uma breve digressão sobre este é importante para demonstrar mais amplamente como as autoridades estavam decididas em evitar os deslocamentos. Frentes de trabalho e controle das fronteiras corporificaram as ações antimigratórias.

\section{Barreiras nas fronteiras: vigiar e controlar}

Nos anos de 1951 e 1952, os chefes políticos e econômicos locais nordestinos tiveram o apoio do Estado, através da política oficial antimigratória, para interferir contra as saídas maciças de migrantes para o Sudeste. Em acréscimo, uma parcela da sociedade das capitais sulistas também parecia insatisfeita, era o que noticiava a imprensa carioca e paulista quase diariamente.

O jornal Correio do Ceará, no início de abril de 1951, dizia-se preocupado com a exploração de "retirantes" por motoristas que rumavam para o Sudeste do país. Equivalente a isso se mostrava satisfeito com as providências tomadas pelo governo, através da fiscalização de caminhões organizada pelo DNER e pelas polícias locais nas principais fronteiras do Nordeste com o Sudeste. Ainda em abril, o mesmo jornal reproduziu uma reportagem da agência meridional que noticiou o "impressionante" êxodo para o Sul do país, alegando, entretanto, que não existia "trabalho compensador" para os nordestinos naquele destino. Por isso, o periódico defendia a imediata realização de obras de emergência para empregar "retirantes" e avisava que as autoridades do Rio tinham acabado de "vedar todas as entradas de caminhões com destino ao Sul do país". ${ }^{21}$

Do outro lado do país, o jornal carioca $A$ Manhã exclamou por meio de reportagem, também em abril, que novas levas de migrantes chegavam ao Rio de Janeiro diariamente. No mesmo dia, o jornal $A$ Notícia divulgou a chegada de trabalhadores nordestinos acrescentando que a polícia apareceu para coagir os migrantes, conduzindo o motorista e o contratador à delegacia. ${ }^{22}$ As chegadas maciças, nos meses de abril e maio de 1951, dos "retirantes nordestinos", que na verdade quase sempre apareciam homogeneizados na regionalidade e desqualificados pela caracterização não de migrante nacional, mas de retirante, geraram incômodo. Não obstante contratadores pudessem se interessar nesses fartos e baratos braços que se dispersavam, como demonstrado na fonte, as autoridades públicas nordestinas tinham claro desinteresse na saída desses braços.

Diante disso, no início de junho, segundo o periódico carioca Correio da Manhã, sugestões apresentadas pelo chefe de polícia ao presidente Getúlio Vargas para "solucionar o problema do êxodo dos flagelados nordestinos para as principais cidades do Sul do país" foram aprovadas, autorizando "os necessários entendimentos entre autoridades federais e estaduais". 23 Dois meses

21 Correio do Ceará, 3/4/1951; Correio do Ceará, 12/4/1951.

22 Arquivo Público do Estado do Rio de Janeiro (APERJ), fundo DPS, Flagelados, fl. 1. A Manhã, 11/04/1951;

APERJ, fundo DPS, Flagelados, fl. 2. A Notícia, 11/4/1951.

23 APERJ, fundo DPS, Flagelados, fl. 3. Correio da Manhã, 1/6/1951. 
depois, propostas mais permanentes foram aprovadas pelo presidente da República para impedir a migração de retirantes, especialmente para as capitais do Rio de Janeiro e São Paulo. Conforme telegrama enviado pelo chefe da polícia do Distrito Federal ao secretário de Segurança Pública do Estado do Rio, o objetivo de tais medidas era "sustar e prevenir o êxodo dos flagelados" que, crescendo rapidamente, tinha "invadido não só a capital da república como outras grandes cidades".

O controle da saída de nordestinos deveria ser feito através da vigilância dos veículos que transportavam retirantes, estipulando-se as seguintes resoluções: propaganda por meio do rádio informando aos migrantes sobre os perigos das propostas de aliciadores e aos motoristas e proprietários de veículos sobre as punições; retorno dos condutores, com seus passageiros, desprovidos de licença do DNER para transportar os migrantes; controle dos conhecidos locais de migração através da instalação de barreiras nas rodovias a cargo do DNER e do DNOCS, reforçadas por policiais estaduais; e obrigatoriedade da apresentação de um documento pelo migrante, fornecido pelo Departamento Nacional de Imigração (DNI), que o habilitasse para seguir percurso, fazendo, taxativamente, retornar aqueles que não portassem a cédula permissiva. ${ }^{24}$

Segundo as propostas acima, vigiar as conduções que transportavam os retirantes resolveria o problema do êxodo, mesmo parcialmente, devido às inúmeras dificuldades que ocasionariam ao movimento migratório. Embora possivelmente muitos desses transportes já fossem irregulares, as ações cautelares só foram maiores quando as autoridades perceberam o volume de gente que chegava às capitais sulistas durante a seca de 1951. Pode-se perceber ainda que as mesmas agências designadas pelo governo para a instalação de frentes de emergência para ocupar trabalhadores DNOCS e DNER - também foram as responsáveis pela instalação das barreiras nas estradas. Entre as principais finalidades do emprego de retirantes em obras estava a ambição de conter os deslocamentos, por diversos motivos, alguns já desenvolvidos até aqui. Além disso, entranhada a esta, como parte de um mesmo projeto, cobrava-se dos mesmos órgãos que empregavam os retirantes um comprometimento de prestar serviço ao Estado também com a vigilância das rodovias, ou seja, a construção de obras no interior e a apreensão de pobres das secas nas fronteiras no Nordeste tinham uma relação umbilical com vistas ao intento antimigratório.

Mesmo assim, a legislação proibitiva, o controle das estradas e cidades, o policiamento, as exigências de documentos para migrar não detiveram a saída dos trabalhadores nordestinos para o Sudeste. O Imprensa Popular reproduziu um depoimento de um migrante nordestino que conseguiu chegar ao Rio de Janeiro depois de enfrentar diversas dificuldades em seu percurso. Em 1952, Manoel Aquilino partiu sem a família em direção à capital carioca. No meio do caminho, teve que usar diversos artifícios para escapar dos guardas que estavam na fronteira de Pernambuco impedindo a passagem de nordestinos rumo ao Sul. Para fugir deles, atravessou a fronteira durante a noite e seguiu em direção a Alagoas, ainda pelo estado de Pernambuco, com o objetivo de conseguir uma passagem de trem. Finalmente, "depois de caminhar por muitos estados", Manoel conseguiu chegar ao Rio. ${ }^{25}$

Certamente, proposição discricionária era a exigência de um documento do DNI para que os nordestinos pudessem se deslocar ao Sudeste. O Tribuna da Imprensa ${ }^{26}$ critica justamente essa última medida, alegando que esta feria a liberdade de ir e vir garantida pela Constituição. Fora isso, segundo o jornal, enquanto caminhões eram barrados nas estradas que ligavam o Nordeste ao Sul

24 APERJ, fundo DPS, Flagelados, fl. 6. A Noite, 3/8/1951.

25 APERJ, fundo DPS, Flagelados, fl.38. Imprensa Popular, 27/3/1952.

26 APERJ, fundo DPS, Flagelados, fl. 9. Tribuna da Imprensa. 17/8/1951 
do país e era exigido de toda pessoa que viajasse para este destino o atestado do DNI, na região Norte, as hospedarias estavam abarrotadas, morrendo diariamente diversas crianças na hospedaria Tapanã - chamada também de hospedaria do diabo.

Dentro do contexto das políticas antimigratórias, se por um lado as fronteiras rumo ao Sudeste eram vigiadas por órgãos federais, estaduais e polícias, os próprios governantes cearenses flexibilizavam negociações e subsídios de passagens para a saída de migrantes para a Amazônia. Em setembro de 1951, segundo o jornal O Liberal, políticos cearenses visitaram as cidades de Belém (PA), Manaus (AM), Macapá (AP) e Boa Vista (RR), sendo recebidos com congratulações por autoridades locais. Durante essa excursão, as principais hospedarias foram visitadas e um plano foi traçado para o envio de trabalhadores cearenses para os seringais da Amazônia com as seguintes proposições: construção da hospedaria em Manaus, organização da viagem e fornecimento de transporte pelo DNI, financiamento do Banco de Crédito da Amazônia para os seringalistas receberem os recém-chegados.

Não obstante o interesse maior do governo federal fosse fixar os trabalhadores em seus locais de origem, a migração em direção à fronteira da extração de látex na Amazônia era admissível e negociável, mesmo em pequena demanda. Em contrapartida, o contragosto das autoridades públicas do Nordeste com a migração de braços se somava ao desagrado de parcela da sociedade citadina do Rio de Janeiro que, conforme o jornal carioca O Radical, criticava o "espetáculo deprimente" causado pela "legião incrível de pedintes" recém-chegados. Esses migrantes nordestinos, segundo o jornal $A$ Noite, tinham "péssimas condições de saúde" e falta de "especialização", por isso, não poderiam aportar nas grandes cidades, devendo ser desviados para o sul de Goiás ou Mato Grosso. ${ }^{27}$

Em São Paulo, centenas de migrantes também eram vistos como endemias andantes. Em início de 1952, o Correio da Manhã noticiou que chegavam diariamente 600 a 700 nordestinos obstruindo a higiene pública, pois muitos eram portadores de "schistosomoses e outras moléstias endêmicas no norte do país". Diante disso, os vereadores locais imediatamente se organizaram para pensar soluções, cogitando a possibilidade de isolar os migrantes "famintos" e "maltrapilhos" por meio da criação de uma hospedaria municipal. ${ }^{28}$

Certamente os parlamentares avaliavam que a hospedaria do São Brás não era mais suficiente para afastar os pobres esfomeados e doentes dos cenários modernos da cidade de São Paulo. Conforme Paulo Fontes, a inauguração da Rio-Bahia, em 1949, tinha facilitado o êxodo através dos paus-de-arara e somente entre os anos 1945 e 1960 passou pela hospedaria do Brás mais de um milhão e meio de pessoas. "A velocidade da urbanização" dos anos 1950 foi proporcional "a intensidade do processo migratório em São Paulo". ${ }^{29}$ Isto é um indício de que, mesmo num contexto de política oficial antimigratória, as pessoas continuaram se deslocando rumo a São Paulo, até porque existia uma parcela que desaprovava os recém-chegados, mas, do outro lado, urbanização e industrialização cobiçavam os braços migrantes.

Mesmo assim, conforme Fontes, os pobres de origem nordestina impactaram o cotidiano na cidade e não raramente a presença de migrantes nordestinos "causava estranheza" e "tensões entre a população já residente e os recém-chegados". Os aspectos da pobreza e do rural incomodavam, fora isso, a cor. Como alega o referido autor, homogeneizavam-se nordestinos no apelido

27 APERJ, fundo DPS, Flagelados, fl.15. A Noite 15/2/1952.

28 APERJ, fundo DPS, Flagelados, fl.13. Correio da Manhã. 10/2/1952.

29 APERJ, fundo DPS, Flagelados, fl.50, 51; FONTES, Paulo. Um Nordeste em São Paulo: Trabalhadores migrantes em São Miguel Paulista. (1945-1966). Rio de Janeiro: FGV, 2008, pp.50, 68. 
de baiano e, mesmo que fossem um grupo considerável, a alcunha deve ponderar o elemento racial presente na designação. Decerto, $60 \%$ dos migrantes eram pardos ou negros e os transeuntes pobres, e em acréscimo negros, causavam incômodo à industrializada, urbana e epopeica cidade de São Paulo. Com isso, no final da década de 1950, cogitou-se novamente frear a entrada de nordestinos em São Paulo, mas jornalistas e parlamentares lembravam da inconstitucionalidade e inviabilidade da proposta que limitava a liberdade de ir e vir garantida pela Constituição ${ }^{30}$.Portanto, a vontade dos chefes políticos do Nordeste de manter os braços nas suas fronteiras de origem teve um reforço do projeto oficial do Estado de sustar o êxodo e, em acréscimo, de parte da imprensa paulista e carioca.

Na seca de 1958, não foram encontrados registros de policiamento de fronteiras e agressiva vigilância como ocorreram nas estiagens de 1951-1953. Deve-se considerar que, se comparadas a estas, as frentes de emergência quintuplicaram na seca de 1958, empregando cerca de meio milhão de trabalhadores, oficialmente. Mais obras significavam ampliação das possibilidades de garantir alistamento e, mesmo que precário, sustento para si e para parentes. Com uma política enfocada no estabelecimento de obras de socorros e assim um número maior de famílias vivendo na dependência delas, é possível que o Estado tenha necessitado de uma menor vigilância de fronteiras com o propósito de evitar o êxodo. Paralelo às obras, as diversas hospedarias existentes, em 1958, também cooperavam para "organizar" a dispersão dos migrantes, mantendo-os suficientemente afastados dos locais onde poderiam ser indesejados. ${ }^{31}$

Assim, pode-se afirmar que, na década de 1950, a política de Estado oficial foi antimigratória. De um lado, obras para o emprego de pobres, de outro, nos primeiros anos daquela década, a vigilância das fronteiras divisórias com o Sudeste. Dentro desse contexto, uma parcela dos migrantes que rumavam para a Amazônia encontrou apoio oficial do Estado. Através de manejos de autoridades públicas locais, com o apoio de setores privados, os governos estaduais do Nordeste e Norte cooperaram no financiamento de passagens e oferta de vagas nas hospedarias. Ademais, deve-se considerar que a migração rumo à Amazônia não feria os propósitos mais amplos das políticas nacionais de integração. O deslocamento em direção a áreas consideradas "vazias" obedecia ao cobiçado fluxo de correntes litoral-sertão.

Demonstrando a heterogeneidade dos planos do Estado, não foi observada uma política oficial de incentivo à migração para o Sudeste do Brasil. Contudo, as pessoas migraram por meio do acionamento de redes de parentesco, solidariedade e outras estratégias individuais e coletivas. Até porque, não obstante a política oficial fosse de controle do êxodo, setores da indústria e comércio desejavam braços nordestinos e o crescimento de São Paulo exercia atração que estimulava os migrantes a enfrentarem as dificuldades do trajeto. Se os particulares da Amazônia, com o apoio dos políticos e subsídio oficial, disputavam a mão de obra migrante pobre da seca, o Sudeste, na década de 1950, exercia um fascínio que motivava os migrantes a partirem por conta própria.

30 APERJ, fundo DPS, Flagelados, fl.50, 51; FONTES, Paulo. Um Nordeste em São Paulo, Op,Cit.,.pp.50, 6870.

${ }^{31}$ As principais hospedarias e postos de migração que receberam cearenses, em 1958, foram criadas depois da seca de 1951: hospedaria Eduardo Ribeiro (Manaus-AM), Hospedaria Tapanã (Belém-PA), Hospedaria Macapá (AP), Hospedaria Copoatá e posto de migração Barra da Corda (Maranhão), posto de migração (Teresina-PI), Hospedaria Getúlio Vargas (Fortaleza-CE), Posto de migração Guarabira (PB); Posto de Migração Petrolina (PE), Posto de Migração Aracajú (SE); Posto de Migração Salvador e Posto de Migração Feira de Santana (BA), Hospedaria Corinto (MG), Posto de Migração Belo Horizonte, Posto de Migração Monte Azul, Posto de Migração Pirapora (MG), Posto de Migração Brasília e Posto de Migração Anápolis (GO), Hospedaria Ilha Grande (DF). Biblioteca do DNOCS. Departamento Nacional de Obras Contra as Secas. Boletim. Rio de Janeiro: DNOCS/MVOP, v.18, n.2, novembro de 1958, p. 44. 
Certamente, as pessoas não se deslocavam somente durante as secas, mas eram nestes anos que o infortúnio era agravado, avolumando a migração de pobres em direção aos outros estados e também aos locais das obras públicas. Então, cearenses e outros nordestinos seguiram para capitais como Belém, Manaus, São Paulo, Rio de Janeiro, Macapá, Boa Vista, Goiás, Brasília, Paraná, mas também para o interior dos estados, alguns com novas frentes industriais como Franca-SP e Serra do Navio-AP (REZENDE, 2012; PAZ, 2014). Numa multiplicidade de direções, os migrantes pobres das secas, na década de 1950, cobriram um país de limites continentais, ocupando-se em obras públicas, atividades agrícolas, extrativistas e industriais, em setores do comércio e outros ofícios, disponibilizando sua força de trabalho, gerando riqueza.

Os planos dos migrantes eram desenhados e redesenhados diversas vezes. Muitos saíam de casa com um destino, mas acabavam trilhando outros caminhos, fosse pela inexistência de emprego, pelas doenças, pela morte de familiares, pela saudade, pelo endividamento, pela frustação dos horizontes de expectativas. Aqui o ato de migrar não é entendido nos termos clássicos que opõem de forma exclusiva origem e destino, que não levam em consideração os movimentos sazonais, de curta distância e duração, e que pensam os migrantes apenas como viajantes de longa distância e sem volta, ou como nômades, ou aventureiros. Ou seja, migração não é algo definido por fronteira geográfica, distância percorrida ou permanência de quem se desloca. É um fenômeno que vai muito além disso, é mais complexo. A experiência explica o movimento. O sujeito tornase migrante. Algo que é definido no desejo, na necessidade, mas também no processo. Essa afirmativa se torna mais compreensível quando se observam a incerteza e a imprevisibilidade que acompanhavam esses trabalhadores.

Dessa forma, constrangidos pelas autoridades a permanecerem em seus estados de origem, diversos trabalhadores cruzaram os limites impostos. Outros, ou pela força das políticas arbitrárias que desejaram controlar os deslocamentos, ou por desejarem ficar perto da família, evitando igualmente as conhecidas dificuldades das longas jornadas interestaduais, foram trabalhar nas centenas de frentes de emergência instaladas pelo governo em todos os estados nordestinos. De um modo ou de outro, pode-se dizer que a instalação de construções públicas durante as secas da década de 1950 foi motivada por esses movimentos migratórios sob a justificativa de que era necessário empregar pobres que poderiam se dispersar.

Assim, os migrantes das secas foram protagonistas na produção de variadas obras por todo o Nordeste, na década de 1950. Ambiguamente, justificada por autoridades públicas e particulares como forma de auxílio e fixação dos sertanejos, toda essa estrutura erguida pelos trabalhadores combinava também com a relativamente acentuada aceleração urbana e industrial que, concentrada especialmente nas grandes capitais do país, seria levada às demais regiões brasileiras, rumo à integração nacional (de acordo com o ideário nacional-desenvolvimentista).

Alistados em obras de açudagem, estradas de rodagem, redes de irrigação, eletricidade, prédios públicos, entre outras, protagonizando a edificação de uma volumosa estrutura em todo o estado. Embora muitos já soubessem da dura lida nas obras públicas, uma labuta em situações sociais e culturais distintas das habituais fora dos anos secos, os trabalhadores procuravam os alistamentos para garantir a sobrevivência. Ocupados nas frentes, labutando em troca de comida, os trabalhadores chamados de cassacos ficavam frente a frente a um cotidiano de convivência com o cenário das máquinas, serviço pesado e mal pago, acampamentos precários, escassez de água até para beber e fome. Tudo isso, somado às condições insalubres nas obras, originava uma equação perigosa que resultava na disseminação de doenças, acidentes de trabalho e até morte. Mas isso é outra parte da história. 


\section{Referências}

CAMPOS, Eduardo. A ação do DNOCS. IN: DNOCS e o Novo Nordeste: uma perspectiva histórica, 1909-1984. Fortaleza: DNOCS, 1985.

CANDIDO, Tyrone Apollo Pontes. Trem da seca: sertanejos, retirantes e operários (1877-1880). Fortaleza: Museu do Ceará, 2005.

CANDIDO, Tyrone. Proletários das secas: arranjos e desarranjos na fronteira do trabalho (18771919). Tese de Doutorado em história, Universidade Federal do Ceará - UFC, Fortaleza, 2014.

CAMARGO, Aspácia. O Nordeste e a Política: diálogo com José Américo de Almeida. Rio de janeiro: Nova Fronteira, 1984.

CARDOSO, Antonio Alexandre Isidio. Nem sina, Nem acaso: a tessitura das migrações entre a Província do Ceará e o território amazônico. Fortaleza, Mestrado em História Social - Universidade Federal do Ceará, 2011.

CARVALHO, Emmanoel Rocha. Barragens de Curema e Mãe $D$ ‘àgua: nos bastidores da construção. João pessoa. Edição do Autor, 2013.

CARVALHO, Rejane V. Aciole. O Estado, a Terra e O Coronelismo. Rio de Janeiro: Coleção Mossoroense. Série C. Volume DCCI, 1991.

COSTA, Pedro Eymar Barbosa; GONÇALVES, Adelaide (Orgs.). Mais borracha para a vitória. Fortaleza: MAUC/NUDOC; Brasília: Ideal Gráfica, 2008.

D’ARAÚJO, Maria Celina. Amazônia e desenvolvimento à luz das políticas governamentais: a experiência dos anos 50. Revista Brasileira de Ciências Sociais. São Paulo: N. 19, ano 7, jun. de 1992. HOBSBAWN. Eric j. Os trabalhadores. Estudos sobre história do operariado. Rio de Janeiro: Paz e Terra, 1981.

LIMA, Aline Silva. Um projeto de "combate às secas", os engenheiros civis e as obras públicas: Inspetoria de Obras contra as Secas - IOCS e a construção do Açude Tucunduba (1909-1919). Dissertação de mestrado. Fortaleza: UFC, 2010.

Unicamp, 2013.

LIMA, Claudio Ferreira. A Questão Regional. Revista Conviver Nordeste Semiárido, v.1, n.6. Fortaleza: DNOCS/BNB-ETENE, 2009, pp.113-114.

LINDEN, Marcel van der. Trabalhadores do mundo: ensaios para uma história global do trabalho. Campinas: Unicamp, 2013.

MEDEIROS FILHO, João e SOUZA, Itamar de. A seca do Nordeste: um falso problema. A política de combate às secas antes e depois da SUDENE. Petrópolis: Vozes, 1988.

MEDEIROS FILHO, João e SOUSA, Itamar de. Os degredados filhos da seca. 2ed. Petrópolis: Vozes, 1983.

NEVES, Frederico de Castro. A multidão e a história: saques e outras ações de massas no Ceará. Rio de Janeiro: Relume Dumará, 2002.

PFAFF, Christine. The Bureau of Reclamation 's: Civilian Conservation Corps Legacy. US Departament Of Interior. Bureau of Reclamation, Denver, Colorado, 2010; PFAFF, Christine. "Happy Days" of the Depression: The Civilian Conservation Corps in Colorado. In Colorado Heritage, Spring 2001. PERROT, Michelle. Os excluídos da História. Operários, Mulheres, Prisioneiros. Rio de Janeiro: Paz e Terra, 1988.

REZENDE, Vinícius Donizete de. Tempo, trabalho e conflito social no complexo coureiro-calçadista 
de Franca-SP (1950-1980). Tese de doutorado. Instituto de Filosofia e Ciências Humanas, Universidade Estadual de Campinas (IFCH-UNICAMP). Campinas, 2012.

RIOS, Kênia Souza. Campos de concentração no Ceará: Isolamento e poder. Fortaleza museu do Ceará/SECULT, 2002.

RUDÉ, G. A Multidão na História: estudo dos movimentos populares na França e na Inglaterra, 1730-1848. Rio de Janeiro: Campus, 1991.

SALMOND. John A. The Civilian Conservation Corps and the Negro. The Journal of American History, Vol. 52, No. 1 (Jun., 1965), pp. 75-88. URL: http://www.jstor.org/stable/1901125. Accessed: 21/1/2015 06:34;

SAVAGE, Mike. "Classe e História do Trabalho". In: BATALHA, C. H. M.; SILVA, F. T. da; FORTES, A. (orgs). Culturas de Classe: identidade e diversidade na formação do operariado. Campinas: Ed. da Unicamp, 2004.

SECRETO. María Verónica. Ceará, a fábrica de trabalhadores: Emigração subsidiada no final do Século XIX. IN: Trajetos. V.IV. Dossiê: trabalho, trabalhadores. Fortaleza: Departamento de História da UFC, 2003.

. Soldados da Borracha. Trabalhadores entre o sertão e a Amazônia no governo Vargas. São Paulo: Editora Fundação Perseu Abramo, 2007.

SILVA, Jeovah Lucas da. As Bênçãos de Deus: a seca como elemento educador para o trabalho (1877-1880). Dissertação de Mestrado, Universidade Federal do Ceará, Fortaleza, 2003.

SCOTT, J. Formas cotidianas da resistência camponesa. Trad. MENESES, M.A. e GUERRA, L. In. Raízes, Campina Grande, vol. (21) º (1), p 10-31, 2002.

SOURCE, Eric Gorham. The Ambiguous Practices of the Civilian Conservation Corps. Social History, Vol. 17, No. 2 (May, 1992), pp. 229-249. URL http://www.jstor.org/stable/4286017. Accessed: 21/01/2015 07:21.

SOUZA, Robério dos Santos. "Se eles são livres ou escravos": escravidão e trabalho livre nos Canteiros da Estrada de São Francisco: Bahia, 1858-1863. Tese (Doutorado em História), Campinas: Universidade Estadual de Campinas, 2013.

THOMPSON, E. P. Costumes em Comum. São Paulo: companhia das letras, 1998. Senhores e Caçadores. Rio de Janeiro: Paz e Terra,1995. 